\title{
Expression of HPIP in epithelial ovarian carcinoma: a clinicopathological study
}

This article was published in the following Dove Press journal:

OncoTargets and Therapy

20 December 2016

Number of times this article has been viewed

\section{Yuping Wang* \\ Fanling Meng* \\ Yunduo Liu \\ Xiuwei Chen}

Department of Gynecology, The Affiliated Tumor Hospital, Harbin Medical University, Harbin, People's Republic of China

*These authors contributed equally to this work
Correspondence: Xiuwei Chen Department of Gynecology, The Affiliated Tumor Hospital, Harbin Medical University, Nangang District, I50 Haping Road, Harbin I5008I, People's Republic of China Tel +86 45I 857I 8031

Email dr_cxw@I26.com
Objectives: Hematopoietic pre-B-cell leukemia transcription factor (PBX)-interacting protein (HPIP) plays an important role in cancer invasion and metastasis. The aim of this study is to investigate the expression of HPIP in epithelial ovarian cancer (EOC).

Patients and methods: Immunohistochemical method was performed using 42 normal ovarian specimens and 145 specimens with EOC. The correlations of HPIP expression with the clinicopathological factors and prognosis of EOC patients were evaluated. Statistical analyses were performed using the chi-square test, multivariate Cox proportional hazard, and KaplanMeier method.

Results: HPIP expression in EOC was higher than that in normal tissues $(P<0.001)$. HPIP expression was significantly associated with histological grade, International Federation of Gynecology and Obstetrics stage, and lymphatic metastasis of EOC $(P<0.05)$. Patients with high HPIP expression had poorer overall survival and disease-free survival $(P<0.001)$ compared with patients with low HPIP expression. Multivariate Cox analysis demonstrated that HPIP was an independent factor for overall survival and disease-free survival $(P<0.05)$.

Conclusion: HPIP may be a valuable biomarker for predicting the prognosis of EOC patients and may serve as a potential target for cancer therapy.

Keywords: hematopoietic pre-B-cell leukemia transcription factor-interacting protein, epithelial ovarian cancer, immunohistochemistry, prognosis

\section{Introduction}

Epithelial ovarian cancer (EOC) is the fifth most common cause of cancer death in women. More than 200,000 new cases of EOC are diagnosed each year worldwide. ${ }^{1}$ In the People's Republic of China, the incidence rate of ovarian cancer was estimated to be 3.6 per 100,000 women in $2005 .^{2}$ EOC is the most common type of ovarian cancer. Most EOC cases are often diagnosed at a late stage, and the 5-year survival rates for patients with advanced EOC were still $<10 \%$ between 2004 and 2008 . $^{3}$ Despite improvement in surgical technology and chemotherapy, the prognosis remains poor, thereby necessitating the identification of biomarkers for predicting prognosis in EOC. Therefore, prognostic and predictive markers are highly important for early EOC diagnosis and for providing targets for treatment.

Hematopoietic pre-B cell leukemia transcription factor (PBX)-interacting protein (HPIP) is a novel oncogene that is overexpressed in various human cancers, such as non-small-cell lung cancer, ${ }^{4}$ human spinal glioblastoma, ${ }^{5}$ thyroid cancer, ${ }^{6}$ gastric cancer, ${ }^{7}$ colorectal cancer, ${ }^{8}$ breast infiltrative ductal carcinoma, ${ }^{9}$ oral carcinogenesis, ${ }^{10}$ liver cancer, ${ }^{11}$ and human melanoma cell. ${ }^{12}$ Recent studies have demonstrated the multifaceted role of HPIP in pathways associated with cancer progression, including transformation, apoptosis, invasion, and metastasis. ${ }^{4,6,13,14}$ HPIP can promote cell 
growth by inhibiting apoptosis and activation of cell cycle progression, accompanied by changes in expression of apoptosis and cell cycle regulators. ${ }^{8}$ However, the biological significance and clinicopathological role of HPIP in EOC remain unclear.

In this study, the HPIP expression in EOC was examined to determine its association with clinicopathological and prognostic significance.

\section{Patients and methods}

\section{Patients and treatment}

Paraffin-embedded tissue samples were collected from 145 patients with EOC diagnosed between September 2009 and July 2011 in the Affiliated Tumor Hospital of Harbin Medical University. All patients underwent maximal cytoreduction followed by platinum-based combination chemotherapy. All the patients intravenously received six to eight cycles of platinum-based combination chemotherapy (at a 3-week interval) 3 weeks after the primary surgery. The chemotherapy regimen consisted of paclitaxel/paclitaxel liposome $135-175 \mathrm{mg} / \mathrm{m}^{2}$ plus nedaplatin $75 \mathrm{mg} / \mathrm{m}^{2}$ given on day 1 . None of these patients were given preoperative radiotherapy or chemotherapy before surgery. Control samples were obtained from 42 patients who underwent hysterectomy plus bilateral or unilateral oophorectomy for uterine fibroids, adenomyosis, or other nonovarian diseases.

The clinical and pathological characteristics of the patients, including age at diagnosis, histological grade, lymph node metastasis, and preoperative serum CA125 level, are described in Table 1. The tumor stage was determined according to the International Federation of Gynecology and Obstetrics (FIGO) staging system. ${ }^{15}$ The histological grade was classified based on the World Health Organization classification standards. ${ }^{16}$

All ovarian cancer patients were periodically followed up for assessing their survival, until death or the completion of the study in December 2014. The patients provided written informed consent, and ethical approval was acquired from the ethical committee of the Harbin Medical University.

\section{Immunohistochemical staining}

Ovarian cancer tissues were formalin fixed and paraffin embedded after being cut into $4 \mu \mathrm{m}$ thick serial sections. These paraffin sections were disposed for immunohistochemistry (IHC) staining. Each slide was independently reviewed by two pathology experts blinded to the clinical data. The paraffin sections were deparaffinized in xylene for 20 minutes and then rehydrated with graded alcohol. The sections were
Table I Association analyses between the expression levels of HPIP and the clinicopathological characteristics of EOC

\begin{tabular}{|c|c|c|c|c|}
\hline \multirow[t]{2}{*}{ Variables } & \multirow{2}{*}{$\begin{array}{l}\text { Patients, } \\
\text { n }\end{array}$} & \multicolumn{2}{|c|}{ HPIP expression } & \multirow[t]{2}{*}{$P$-value } \\
\hline & & Low & High & \\
\hline \multicolumn{5}{|l|}{ All cases } \\
\hline Age (years) & & & & 0.586 \\
\hline$\leq 55$ & 76 & 23 & 53 & \\
\hline$>55$ & 69 & 18 & 51 & \\
\hline FIGO stage & & & & 0.029 \\
\hline I-II & 34 & 15 & 19 & \\
\hline III-IV & 111 & 26 & 85 & \\
\hline Histological grade & & & & $<0.001$ \\
\hline GI & 40 & 22 & 18 & \\
\hline $\mathrm{G} 2 / \mathrm{G} 3$ & 105 & 19 & 86 & \\
\hline Histological type & & & & 0.391 \\
\hline Serous & 105 & 27 & 78 & \\
\hline Mucinous & 25 & 7 & 18 & \\
\hline Endometrioid & 10 & 5 & 5 & \\
\hline Clear cell & 5 & 2 & 3 & \\
\hline CAI $25(\mathrm{U} / \mathrm{mL})$ & & & & 1.000 \\
\hline$\leq 35$ & 25 & 7 & 18 & \\
\hline$>35$ & 120 & 34 & 86 & \\
\hline Lymph node metastasis & & & & $<0.001$ \\
\hline No & 109 & 39 & 70 & \\
\hline Yes & 36 & 2 & 34 & \\
\hline
\end{tabular}

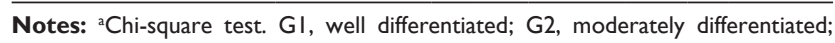
G3, poorly differentiated.

Abbreviations: HPIP, hematopoietic pre-B cell leukemia transcription factor (PBX)-interacting protein; EOC, epithelial ovarian cancer; FIGO, International Federation of Gynecology and Obstetrics.

immersed for 10 minutes in 3\% hydrogen peroxide, as well as inactivated endogenous peroxidase. All slides were autoclaved at $121^{\circ} \mathrm{C}$ to retrieve the antigenicity for 4 minutes and then immersed in $0.01 \mathrm{~mol} / \mathrm{L}$ citrate buffer ( $\mathrm{pH} \mathrm{6.0)}$, after cooling down to room temperature. These slides were incubated overnight with rabbit anti-HPIP antibodies (Abcam, Cambridge, MA, USA) at a dilution of 1:200 inside the humidor at $4^{\circ} \mathrm{C}$, immobilized thrice with phosphate-buffered saline, and then incubated with rabbit secondary antibodies for 20 minutes inside the humidor under room temperature. HPIP expression was visualized with 3,3-diaminobenzidine tetrahydrochloride, counterstained with Mayer's hematoxylin, dehydrated in gradient alcohol, sealed with neutral resin, and then kept in the oven at $60^{\circ} \mathrm{C}$ for 48 hours. A paraffinembedded block of a proven cervical cancer was used as a positive control. The negative control slides were stained with rabbit serum instead of primary antibodies.

Staining intensity used was as follows: 0 (no staining); 1 (weak staining); 2 (moderate staining); and 3 (strong staining). The percentage of staining was scored as $0(<5 \%$ positive cells), 1 ( $5 \%-25 \%$ positive cells), 2 ( $25 \%-50 \%$ positive cells), $3(51 \%-75 \%$ positive cells), and 4 ( $>75 \%$ positive cells). 
The final score as mentioned earlier was multiplied. For HPIP, we adopted a score of $0-2$ as negative and a score of $3-12$ as positive. $^{?}$

\section{Statistical analysis}

The Pearson's chi-square test was used to analyze the association of HPIP expression levels with various clinicopathological factors. The associations between HPIP expression and the prognosis of patients with epithelial ovarian carcinoma were calculated using the Kaplan-Meier method and the log-rank test. Multivariate survival was performed using a Cox regression model to analyze the independent prognosis factors. In all tests, $P$-value $<0.05$ was indicated to be statistically significant. All statistical analyses were conducted using SPSS 22.0 software (IBM Corporation, Armonk, NY, USA).

\section{Results HPIP expression in EOC}

HPIP expression was significantly higher in the EOC tissues than in the normal ovarian tissues $(P<0.001)$. Figure $1 \mathrm{~A}-\mathrm{D}$ shows representative IHC results of HPIP staining in EOC.
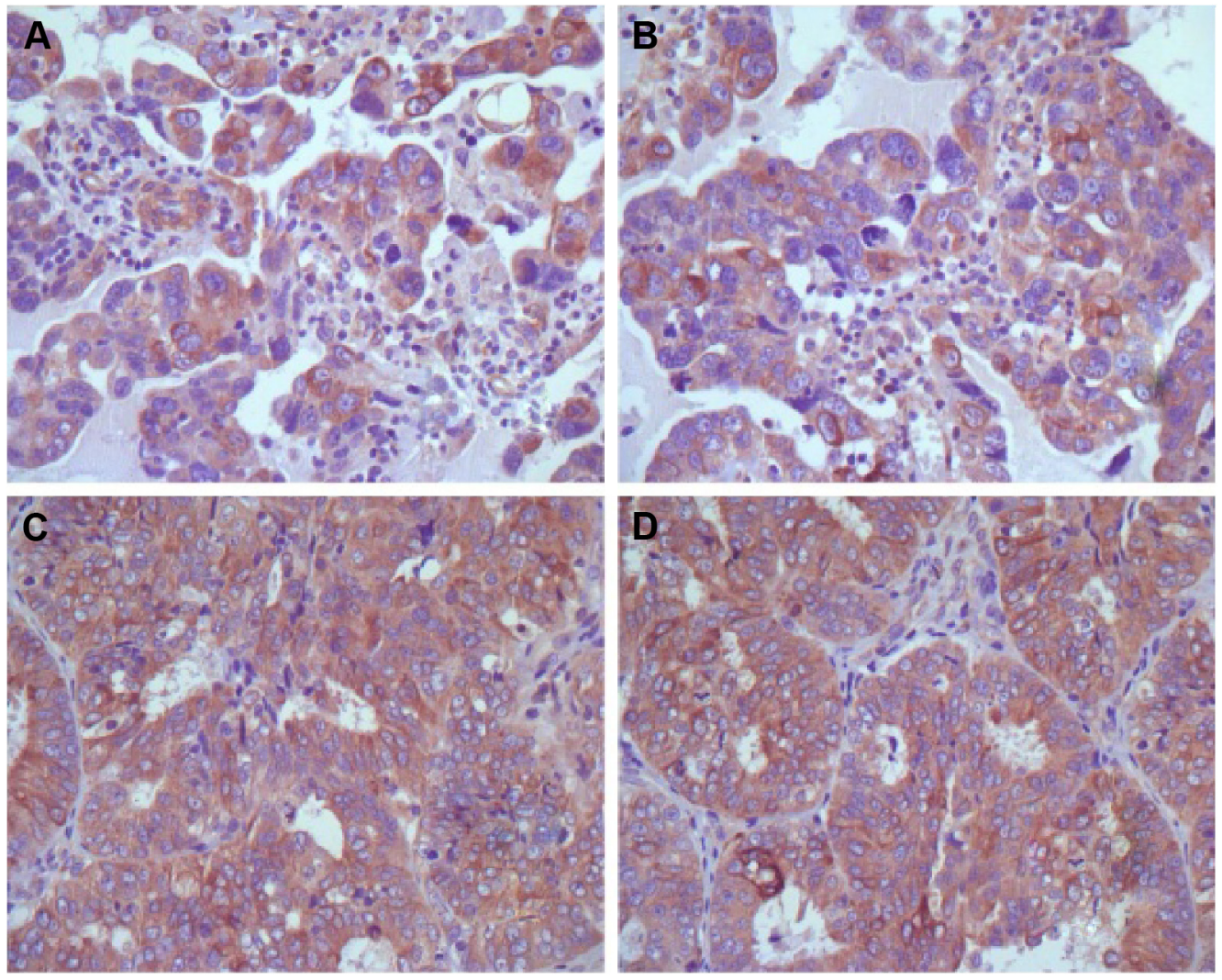

The HPIP expression was localized in the cytoplasm of tumor cells. Of the 145 EOC cases, 41 (28.3\%) and 104 (71.7\%) showed negative and positive HPIP expression, respectively. Furthermore, positive HPIP expression was significantly associated with FIGO stage $(P=0.029)$, histological grade $(P<0.001)$, and lymph node metastasis $(P<0.001)$. However, HPIP expression did not correlate with age $(P=0.586)$ and preoperative serum CA125 level (Table 1; $P=1.000$ ).

\section{Relationship between HPIP expression and patient survival}

The patients with HPIP low expression had a significantly better overall survival (OS) and disease-free survival (DFS) compared with patients with high HPIP expression (both $P<0.001$; Table 2, Figure 2).

Multivariate analysis demonstrated that HPIP high expression was an independent prognostic factor for both $\mathrm{OS}$ and DFS (Table 3; $P=0.005$ and $P<0.001$, respectively).

\section{Discussion}

We investigated HPIP expression by IHC in 145 EOC specimens. We demonstrated that high HPIP expression

Figure I Immunohistochemical staining of HPIP in EOC specimens $(4 \times 100)$.

Notes: (A and B) Low expression of HPIP in EOC; (C and $\mathbf{D})$ high expression of HPIP in EOC.

Abbreviations: HPIP, hematopoietic pre-B cell leukemia transcription factor (PBX)-interacting protein; EOC, epithelial ovarian cancer. 
Table 2 Univariate survival analysis of OS and DFS in 145 patients with EOC

\begin{tabular}{|c|c|c|c|c|c|c|c|}
\hline \multirow[t]{2}{*}{ Variables } & \multirow[t]{2}{*}{$\mathbf{n}$} & \multicolumn{2}{|l|}{ os } & \multirow[t]{2}{*}{$P$-value ${ }^{a}$} & \multicolumn{2}{|l|}{ DFS } & \multirow[t]{2}{*}{$P$-value } \\
\hline & & $\begin{array}{l}\text { Mean } \pm \text { SE } \\
\text { (months) }\end{array}$ & $95 \% \mathrm{Cl}$ & & $\begin{array}{l}\text { Mean } \pm \text { SE } \\
\text { (months) }\end{array}$ & $95 \% \mathrm{Cl}$ & \\
\hline Age (years) & & & & 0.319 & & & 0.417 \\
\hline$\leq 55$ & 76 & $5 I \pm 3$ & $45-56$ & & $40 \pm 3$ & $34-46$ & \\
\hline$>55$ & 69 & $47 \pm 3$ & $42-52$ & & $37 \pm 2$ & $32-42$ & \\
\hline FIGO stage & & & & $<0.001$ & & & $<0.001$ \\
\hline I+II & 34 & $65 \pm 4$ & $58-72$ & & $56 \pm 4$ & $48-65$ & \\
\hline III + IV & 111 & $44 \pm 2$ & $4 I-48$ & & $33 \pm 2$ & $29-37$ & \\
\hline Histological grade & & & & $<0.001$ & & & $<0.001$ \\
\hline GI & 40 & $64 \pm 3$ & $57-70$ & & $52 \pm 4$ & $45-60$ & \\
\hline $\mathrm{G} 2 / \mathrm{G} 3$ & 105 & $43 \pm 2$ & $39-47$ & & $33 \pm 2$ & $29-37$ & \\
\hline Histological type & & & & 0.960 & & & 0.946 \\
\hline Serous & 105 & $49 \pm 2$ & $45-53$ & & $38 \pm 2$ & $34-42$ & \\
\hline Mucinous & 25 & $48 \pm 5$ & $39-57$ & & $39 \pm 5$ & $30-48$ & \\
\hline Endometrioid & 10 & $47 \pm 8$ & $32-63$ & & $42 \pm 9$ & $25-58$ & \\
\hline Clear cell & 5 & $50 \pm 6$ & $38-62$ & & $36 \pm 8$ & $21-52$ & \\
\hline CAI 25 (U/mL) & & & & 0.882 & & & 0.958 \\
\hline$\leq 35$ & 25 & $48 \pm 5$ & $39-57$ & & $39 \pm 5$ & $30-48$ & \\
\hline$>35$ & 120 & $50 \pm 2$ & $45-54$ & & $38 \pm 2$ & $34-43$ & \\
\hline Lymph node metastasis & & & & 0.002 & & & $<0.001$ \\
\hline No & 109 & $53 \pm 2$ & $48-57$ & & $42 \pm 2$ & $38-47$ & \\
\hline Yes & 36 & $38 \pm 3$ & $32-44$ & & $27 \pm 3$ & $22-32$ & \\
\hline HPIP & & & & $<0.001$ & & & $<0.001$ \\
\hline Low expression & 41 & $63 \pm 3$ & $57-69$ & & $54 \pm 4$ & $47-62$ & \\
\hline High expression & 104 & $43 \pm 2$ & $39-47$ & & $32 \pm 2$ & $28-35$ & \\
\hline
\end{tabular}

Notes: aLog-rank test. GI, well differentiated; G2, moderately differentiated; G3, poorly differentiated.

Abbreviations: OS, overall survival; DFS, disease-free survival; EOC, epithelial ovarian cancer; CI, confidence interval; SE, standard error; FIGO, International Federation of Gynecology and Obstetrics; HPIP, hematopoietic pre-B cell leukemia transcription factor (PBX)-interacting protein.

was significantly associated with tumor progression and poor prognosis. This finding indicates that HPIP may be an independent prognostic biomarker. To our knowledge, this is the first study to investigate the association of clinicopathological characteristics and prognostic significance of HPIP expression in EOC.

A

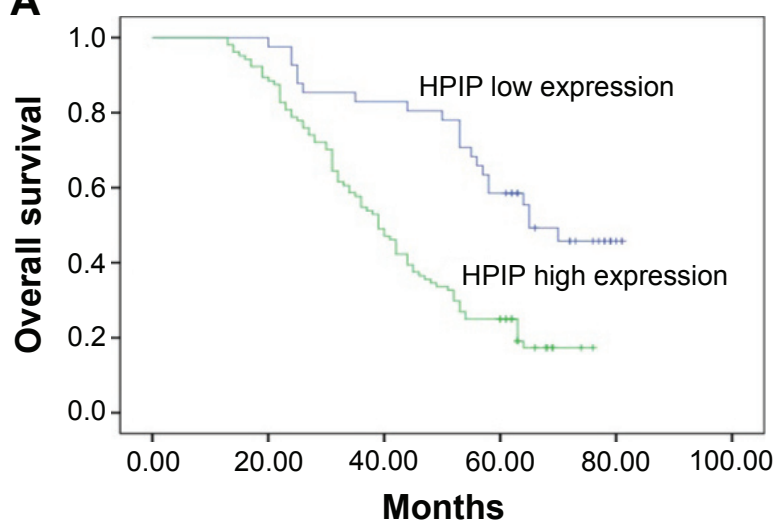

We investigated HPIP expression in EOC tissue and normal ovarian epithelium tissue by IHC. We observed that high HPIP expression was associated with FIGO stage, lymph node metastasis, and histological grade. Our data showed that patients with high HPIP expression showed unfavorable OS and DFS. In addition, HPIP may be an independent

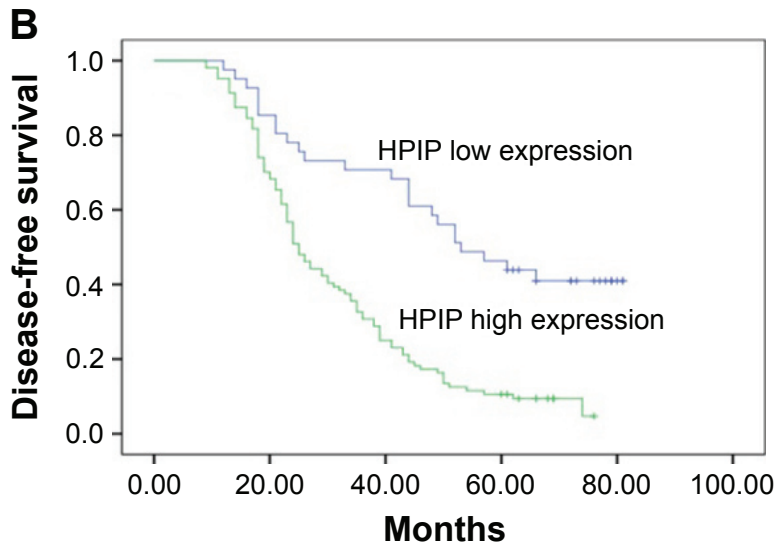

Figure 2 Kaplan-Meier analysis of overall survival and disease-free survival related to the expression of HPIP.

Notes: Patients with high expression of HPIP had a poorer prognosis than patients with low expression of HPIP. (A) Overall survival curves of the EOC according to their HPIP expression status, $P<0.00$ I; (B) disease-free survival curves of the EOC patients according to their HPIP expression status, $P<0.00 \mathrm{I}$.

Abbreviations: HPIP, hematopoietic pre-B cell leukemia transcription factor (PBX)-interacting protein; EOC, epithelial ovarian cancer. 
Table 3 Multivariate survival analysis of OS and DFS in 145 patients with EOC

\begin{tabular}{|c|c|c|c|c|c|c|}
\hline \multirow[t]{2}{*}{ Variables } & \multicolumn{3}{|l|}{ OS } & \multicolumn{3}{|l|}{ DFS } \\
\hline & $\operatorname{Exp}(B)$ & $95 \% \mathrm{Cl}$ & $P$-value ${ }^{a}$ & $\operatorname{Exp}(B)$ & $95 \% \mathrm{Cl}$ & $P$-value ${ }^{a}$ \\
\hline FIGO stage & 2.601 & $1.426-4.743$ & 0.002 & 2.540 & $1.517-4.253$ & $<0.001$ \\
\hline HPIP & 2.043 & I.235-3.377 & 0.005 & 2.397 & I.489-3.859 & $<0.001$ \\
\hline Histological grade & 2.116 & $1.234-3.626$ & 0.006 & 1.645 & $1.030-2.626$ & 0.037 \\
\hline
\end{tabular}

Note: ${ }^{\text {aCox }}$ regression test.

Abbreviations: OS, overall survival; DFS, disease-free survival; EOC, epithelial ovarian cancer; Cl, confidence interval; FIGO, International Federation of Gynecology and Obstetrics; HPIP, hematopoietic pre-B cell leukemia transcription factor (PBX)-interacting protein.

prognostic factor in EOC. These results indicate that HPIP expression plays an important role in EOC development and is significantly associated with an independent poor prognostic factor. Our results are consistent with the previous findings on the roles of HPIP in tumor progression in various cancers. ${ }^{17-19}$ All these findings suggest an important tumor biological role of HPIP in tumorigenesis and malignant transformation.

To date, some studies can explain the mechanisms by which HPIP promotes cancer development. High expression of HPIP leads to activation of some oncogenes, such as cyclin A, cyclin B, and cyclin D1 in some cell lines. Recent studies also demonstrated a key role of HPIP in signal transduction pathways, thereby promoting cell proliferation. Wang et $\mathrm{al}^{6}$ demonstrated that HPIP may have a vital function in PI3K/AKT signaling transduction pathways, which regulate multiple biological behavior, such as apoptosis, cell carcinogenesis, and epithelial-mesenchymal transition. Some studies have inferred that HPIP can mediate specific estrogen receptor signaling in several cancer cells..$^{13,14,20,21}$ Feng et $\mathrm{al}^{8}$ speculated that HPIP could activate MAPK/ERK pathway in colorectal cancer cell, thereby promote tumor proliferation and migration. ${ }^{8}$ These research studies provide important information that demonstrates the mechanism by which HPIP contributes to carcinogenesis and tumor development.

The significant role of HPIP in cancer also suggests this as a potential target for anticancer therapies. Blocking of HPIP expression can significantly inhibit cell anchorage-dependent and proliferation of human hepatic carcinoma cell. ${ }^{11}$ Wang et $\mathrm{al}^{6}$ demonstrated that knockdown of HPIP could inhibit thyroid carcinoma cell proliferation, migration/invasion, and epithelial-mesenchymal transition. HPIP knockdown also reduces thyroid tumor growth in nude mice. ${ }^{6}$ These studies indicate HPIP as a target gene for therapy of EOC.

The present study is the first to illustrate HPIP as a potential biomarker in predicting tumor progression and EOC prognosis. However, this study still has several limitations; in particular, this study is relatively small scale and involves a short follow-up period for patients. Therefore, a well-designed study with a large size of EOC samples is needed. Further studies should investigate the role of HPIP in various ovarian carcinoma cell lines and determine whether combining HPIP with other molecular markers can improve the outcome of EOC patients.

\section{Conclusion}

HPIP is overexpressed in EOC patients, and high HPIP expression is related to unfavorable prognosis in EOC.

\section{Acknowledgments}

The authors would like to thank Doctor Ruibo Zhao for the IHC evaluation. This work was supported by grants from the National Natural Science Foundation of China (81201613), the Haiyan Foundation of the Affiliated Tumor Hospital of Harbin Medical University (JJZ2011-04), Harbin Science and technology innovation talents special fund project (2015RAXYJ054), and the Research Fund for the Xiansheng Antitumor vascular-targeted therapy of CSCO (Y-S2015-003). The funders had no role in study design, data collection and analysis, decision to publish, or preparation of the manuscript.

\section{Disclosure}

The authors report no conflicts of interest in this work.

\section{References}

1. Torre LA, Bray F, Siegel RL, Ferlay J, Lortet-Tieulent J, Jemal A. Global cancer statistics, 2012. CA Cancer J Clin. 2015;65(2):87-108.

2. Kim K, Zang R, Choi SC, Ryu SY, Kim JW. Current status of gynecological cancer in China. J Gynecol Oncol. 2009;20(2):72-76.

3. Ovarian cancer, five-year stage-specific relative survival rates (2004-2008). J Natl Cancer Inst. 2011;103(17):1287.

4. Pan J, Qin Y, Zhang M. HPIP promotes non-small cell lung cancer cell proliferation, migration and invasion through regulation of the Sonic hedgehog signaling pathway. Biomed Pharmacother. 2016;77: 176-181.

5. Wang D, Wang L, Zhou Y, Zhao X, Xiong H. The involvement of hematopoietic pre-B cell leukemia transcription factor-interacting protein in regulating epithelial-mesenchymal transition of human spinal glioblastoma. Tumour Biol. 2015;37(5):5897-5903.

6. Wang SC, Chai DS, Chen CB, Wang ZY, Wang L. HPIP promotes thyroid cancer cell growth, migration and EMT through activating PI3K/AKT signaling pathway. Biomed Pharmacother. 2015;75:33-39. 
7. Feng Y, Li L, Zhang X, et al. Hematopoietic pre-B cell leukemia transcription factor interacting protein is overexpressed in gastric cancer and promotes gastric cancer cell proliferation, migration, and invasion. Cancer Sci. 2015;106(10):1313-1322.

8. Feng Y, Xu X, Zhang Y, et al. HPIP is upregulated in colorectal cancer and regulates colorectal cancer cell proliferation, apoptosis and invasion. Sci Rep. 2015;5:9429.

9. Bugide S, David D, Nair A, et al. Hematopoietic PBX-interacting protein (HPIP) is over expressed in breast infiltrative ductal carcinoma and regulates cell adhesion and migration through modulation of focal adhesion dynamics. Oncogene. 2015;34(35):4601-4612.

10. Okada S, Irie T, Tanaka J, et al. Potential role of hematopoietic pre-B-cell leukemia transcription factor-interacting protein in oral carcinogenesis. J Oral Pathol Med. 2015;44(2):115-125.

11. Xu X, Jiang C, Wang S, et al. HPIP is upregulated in liver cancer and promotes hepatoma cell proliferation via activation of $\mathrm{G} 2 / \mathrm{M}$ transition. IUBMB Life. 2013;65(10):873-882.

12. Nishimura K, Hirokawa YS, Mizutani H, Shiraishi T. Reduced heterochromatin protein 1-beta (HP1beta) expression is correlated with increased invasive activity in human melanoma cells. Anticancer Res. 2006; 26(6B):4349-4356.

13. Shostak K, Patrascu F, Goktuna SI, et al. MDM2 restrains estrogenmediated AKT activation by promoting TBK1-dependent HPIP degradation. Cell Death Differ. 2014;21(5):811-824.

14. Wang X, Yang Z, Zhang $H$, et al. The estrogen receptor-interacting protein HPIP increases estrogen-responsive gene expression through activation of MAPK and AKT. Biochim Biophys Acta. 2008;1783(6): $1220-1228$
15. Benedet JL, Bender H, Jones H 3rd, Ngan HY, Pecorelli S. FIGO staging classifications and clinical practice guidelines in the management of gynecologic cancers. FIGO Committee on Gynecologic Oncology. Int J Gynaecol Obstet. 2000;70(2):209-262.

16. Tavassoeli FA. WHO Classification of Tumours, Pathology and Genetics: Tumours of the Breast and Female Genital Organs. Lyon: IARC; 2003.

17. Manavathi B, Lo D, Bugide S, et al. Functional regulation of pre-B-cell leukemia homeobox interacting protein 1 (PBXIP1/HPIP) in erythroid differentiation. J Biol Chem. 2012;287(8):5600-5614.

18. Xu X, Fan Z, Kang L, et al. Hepatitis B virus X protein represses miRNA148a to enhance tumorigenesis. J Clin Invest. 2013;123(2):630-645.

19. Abramovich C, Chavez EA, Lansdorp PM, Humphries RK. Functional characterization of multiple domains involved in the subcellular localization of the hematopoietic Pbx interacting protein (HPIP). Oncogene. 2002;21(44):6766-6771.

20. Selina AK, Murat K, Emre K, Ismail M, Bunyami U, Cemal G. The relationship between estrogen receptors and microtubule dynamics in post-menopausal rat brain. Acta Histochem. 2015;117(8):747-751.

21. Yu YH, Siao FP, Hsu LC, Yen PH. TEX11 modulates germ cell proliferation by competing with estrogen receptor beta for the binding to HPIP. Mol Endocrinol. 2012;26(4):630-642.
OncoTargets and Therapy

\section{Publish your work in this journal}

OncoTargets and Therapy is an international, peer-reviewed, open access journal focusing on the pathological basis of all cancers, potential targets for therapy and treatment protocols employed to improve the management of cancer patients. The journal also focuses on the impact of management programs and new therapeutic agents and protocols on

\section{Dovepress}

patient perspectives such as quality of life, adherence and satisfaction The manuscript management system is completely online and includes a very quick and fair peer-review system, which is all easy to use. Visit http://www.dovepress.com/testimonials.php to read real quotes from published authors. 